\title{
Stem Cell Research and Cancer Stem Cells Moorthy P.Ponnusamy
}

Department of Biochemistry and Molecular Biology, University of Nebraska Medical Center, Omaha, NE 68198-5870, USA

Open access journals are an important source since they are available online and are easy an access to all the scientists especially for the growing young scientists. The stem cells and regenerative medicine research is an emerging field in biology. The journal of Tissue Science and Engineering is one of the open access journal in OMICS group which publish many research and review articles in the field of Stem cells, and Tissue science and Engineering.

\section{Cancer Stem Cells}

Stem cells are specialized and undifferentiated cells capable of self-renewal, which undergo asymmetric division giving rise to differentiated progenitor cells [1]. The adult stem cells undergo rapid proliferation when it needs to regenerate the specialized tissues [1]. Recent evidences demonstrate that a small population of stem-like cells arises from tumors called cancer stem cells [2]. Most recently, much attention has been focused on the role of cancer stem cells in the formation, propagation and progression of various tumors. However identification of the cancer stem cells has remained elusive, as the CSCs are usually asymptomatic and identified only at a later stage. Cancer stem cells are capable of self-renewal and may originate from normal stem cells, progenitor cells and differentiated cancer cells. The most widely accepted hypothesis is that cancers are driven by a subset of highly tumorigenic cells ( $<5 \%$ of the total tumor cell population) with stem cell properties known as cancer stem cells which have an acquired property of sustaining growth from the neoplastic clone. Other than the similarity to normal stem cells in the self-renewal and differentiation property, CSC also possesses properties such as high motility, increased proliferative rate and drug resistance. The selfrenewal process is maintained by signaling pathways such as Wnt, Hedgehog, Notch, $\beta$ catenin and Oct4 [3]. Due to the drug resistance property of cancer stem cells, tumors relapseis seen in patients after chemotherapy. Therefore, signaling pathways that control CSCs alone have to be explored for further understanding of developmental processes and may prove to be important therapeutic targets for cellular reprogramming and tumor genesis.

\section{Molecular Evidence for Cancer Stem Cells}

The biomarkers for the cancer stem cells are CD34, CD133, CD24, CD44, CD29 and CD31. Recently CD44+ CSCs have been implicated in the phenomenon of tumor progression and metastasis, which also express high levels of nuclear BMI-1 (a stem cell related gene implicated in carcinogenesis of leukemia, lymphomas, lung and breast cancer). The collective evaluation of both CD44 and BMI-1 can lead to precise evaluation and characterization of the CSC population in the tumor cellular architecture. Very recently, ALDH1 has been propounded as a marker for CSCs with the ALDH1 + cells exhibiting high selfrenewal capacity and radio resistance. While on one hand, these molecular markers can lead to an early identification of the CSC tumor population, on the other hand, they can also predict the tumor behavior, aggressiveness and suggest the prognosis. One such biomarker group is a class of small non-coding RNAs, termed microRNAs which suppress the translation of target mRNAs by binding to their $3^{\prime}$ un translated region [4]. MicroRNA and CSCs are two scientific areas of intense interest at the present time. Therefore, early detection of the CSC specific mRNA will have an effective bearing and can definitely alter the current treatment protocols. Characterization and identification of CSCs by means of specific new molecular bio markers can guide us in developing efficacious targeted therapies to prevent tumor recurrences.

\section{Cancer Stem Cells has Differentiation Capacity}

In recent years the scientist communities have been challenged by numerous questions about the cancer stem cells and its differentiation. One of the important questions is whether the cancer stem cells have a capacity to differentiate into specific lineages? It has been proved that the adult stem cells are undifferentiated stem cells, identified in most of the organs. These cells are capable of differentiating into the specialized cell types of tissue or organ. The major roles of adult stem cells in a living organism are to maintain and repair the tissue in which they are found. Scientists also use the term somatic stem cell instead of adult stem cell, where somatic refers to cells of the body. Recent evidence showed that various tumors consist of heterogeneous population of cells showing difference in marker expression and growth capacities $[5,6]$. The cancer stem cell hypothesis proposed that the heterogeneity is because of ongoing differentiation within tumors. Based on this evidence, scientists have invented that cancer stem cells are involved in the multi-lineage differentiation [7]. Vermeulen et al. showed that single-cell cloning of colon cancer stem cells reveals a multi-lineage differentiation capacity [7]. They have isolated the cancer stem cells based on the markers and grown as spheroid cultures. They have further shown the differentiated progeny resides in the single cancer stem cell and these single cell clone form adenocarcinoma on xenotransplantation [7].

\section{Conclusion}

Overall, the evidence revealed that heterogeneity in tumors with respect to both differentiation grade and differentiation phenotype is a clonal trait. More importantly, the identification of cancer stem cell with specific maintenance marker and its role in the differentiation would provide critical information for advancing towards the longterm goal of developing novel therapeutic strategies will reduce the incidence of tumor recurrence for cancer patients.

\section{References}

1. Blau HM, Brazelton TR, Weimann JM (2001) The evolving concept of a stem cell: entity or function? Cell 105: 829-841.

Corresponding author: MoorthyP.Ponnusamy, PhD., Department of Biochemistry and Molecular Biology, University of Nebraska Medical Center, Omaha, NE 681985870, USA, Tel: 402-559-7754; Fax 402-559-6650; E-mail: mpalanim@unmc.edu

Received August 31, 2011; Accepted October 22, 2011; Published October 24, 2011

Citation: Ponnusamy MP (2010) Stem Cell Research and Cancer Stem Cells. J Tissue Sci Eng 2:104e. doi:10.4172/2157-7552.1000104e

Copyright: (C) 2010 Ponnusamy MP. This is an open-access article distributed under the terms of the Creative Commons Attribution License, which permits unrestricted use, distribution, and reproduction in any medium, provided the original author and source are credited. 
2. Reya T, Morrison SJ, Clarke MF, Weissman IL (2001) Stem cells, cancer, and cancer stem cells. Nature 414: 105-111.

3. Kazi R, Sayed SI, Dwivedi RC (2010) Cancer stem cells: an enigma in head and neck cancer. J Cancer Res Ther 6: 411-413.

4. Iorio MV, Ferracin M, Liu CG, Veronese A, Spizzo R, et al. (2005) MicroRNA gene expression deregulation in human breast cancer. Cancer Res 65: 70657070
5. Dalerba P, Cho RW, Clarke MF (2007) Cancer stem cells: models and concepts. Annu Rev Med 58: 267-284.

6. Vermeulen L, Sprick MR, Kemper K, Stassi G, Medema JP (2008) Cancer stem cells--old concepts, new insights. Cell Death Differ 15: 947-958.

7. Vermeulen L, Todaro M, de Sousa MF, Sprick MR, Kemper K, et al. (2008) Single-cell cloning of colon cancer stem cells reveals a multi-lineage differentiation capacity. Proc Natl Acad Sci USA 105: 13427-13432. 